\title{
O SISTEMA FINANCEIRO COMO INSTRUMENTO PARA A REDUÇÃO DA DESIGUALDADE DE RENDA DO BRASIL (1995-2014)
}

\section{The financial system as an instrument for reducing Brazil's income inequality}

Chinara Mendes Schinaider (UFV) Luccas Assis Attílio (UFOP)

Informações do artigo

Recebido em 01/03/2018.

Aceito em 01/04/2018.

doi> 10.25247/2447-861X.2018.n243.p8-31

\begin{abstract}
Resumo
O objetivo desse artigo é avaliar a atuação do sistema financeiro como mecanismo para a redução dos níveis de desigualdade de renda no Brasil, compreendendo o período de 1995 a 2014. A análise econométrica ocorre por regressões múltiplas com o método de Mínimos Quadrados Ordinários (MOO). Os resultados das estimações sugerem que o crédito é negativamente relacionado à desigualdade de renda, evidenciando a importância do desenvolvimento do sistema financeiro, através da expansão do acesso ao crédito, como instrumento para a redução da desigualdade de renda.

Palavras-Chave: Crédito. Desigualdade. Brasil.

Abstract

The objective of this article is to evaluate the performance of the financial system as a mechanism to reduce the levels of income inequality in Brazil, covering the period from 1995 to 2014. Econometric analysis occurs by multiple regressions using the Ordinary Least Squares (OLS). The results of the estimates suggest that credit is negatively related to income inequality, showing the importance of the development of the financial system, through the expansion of access to credit, as a tool to reduce income inequality.
\end{abstract}

Keywords: Credit. Inequality. Brazil. 


\section{Introdução}

O Brasil possui um grande percentual de pobres e é considerado um dos países mais desiguais do mundo, levando em consideração a distribuição de renda. Não obstante, esse quadro vem-se transformando. Nos últimos anos, o índice de mensuração da desigualdade de renda - gini - apresentou níveis significativos de redução, mesmo que ainda se mostre muito elevado.

Estudos recentes identificam que o aumento recente ao acesso a serviços bancários destinados à população mais carente está sendo acompanhado por um alívio na questão relativa à pobreza (seção 3). Ademais, isso vem ainda com opção de possibilidades de investimentos e, assim, promover o crescimento da renda da população mais pobre.

O objetivo desse artigo é, portanto, investigar a atuação do setor financeiro brasileiro, no período de 1995 a 2014, como instrumento no combate à disparidade de renda. Iremos analisar a literatura relativa ao tema juntamente com análises quantitativas de variáveis relevantes para compreender o processo de equalização da renda. Adicionalmente, um modelo econométrico é construído, utilizando regressões múltiplas com Mínimos Quadrados Ordinários (MOO) a fim de captar a relação entre desigualdade de renda e o setor financeiro brasileiro.

Os resultados denotam que o sistema financeiro, representado pela variável saldo de carteira de crédito em relação ao PIB, é negativamente relacionado com a desigualdade de renda. Sendo assim, os resultados atestam a importância da expansão do acesso ao crédito direcionado aos mais pobres, com o intuito de reduzir a desigualdade de renda.

Um dos fatores que contribuíram para a redução da desigualdade de renda no Brasil foi o direcionamento de políticas voltadas para a oferta de crédito para os mais pobres. Sendo assim, podemos verificar a importância desta pesquisa, pois o sistema financeiro é um instrumento que permite a alocação de recursos para o seu uso em fins produtivos, podendo, assim, colaborar no combate à desigualdade de renda.

O artigo está dividido da seguinte forma: além da introdução, ele é composto por mais quatro seções. A seção 2 analisa a economia brasileira do período da hiperinflação até o primeiro governo Dilma. A seção 3 enfatiza o sistema financeiro e sua relação com a desigualdade de renda. A seção 4 apresenta o referencial teórico e o modelo econométrico. Por fim, a seção 5 realiza uma síntese que conclui este trabalho. 


\section{Evolução da economia brasileira}

Hiperinflação e o Plano Real

Na primeira metade dos anos 90, o Brasil foi marcado por um período de profunda recessão. A inflação havia ultrapassado a casa dos $80 \%$ ao mês e a economia, que entre 1930 1980 crescera a uma taxa média de 7\%, passava por uma estagnação que se arrastava desde meados de 1980.

A conjuntura geral que destinou à hiperinflação no Brasil está estritamente relacionada com a crise econômica dos anos 80 e possui semelhanças àquelas encontradas em países que passaram pela mesma situação no passado. Segundo Bresser Pereira e Nakano (1991, p. 90), a dívida externa acumulada nos anos 70, o choque externo de 1979 (segundo choque do petróleo e choque dos juros) e a suspensão de financiamentos externos desde 1982 tiveram, juntos, consequências semelhantes. Tal crise, evidenciada no final da década de 8o, foi agravada principalmente pela desvalorização da moeda local, a fim de manter o país competitivo; e pelo aumento do dinheiro em circulação com o intuito de financiar a dívida externa.

Concebido em 1994, o Plano Real, como mencionado, surgiu em um ambiente conturbado para a economia brasileira. O objetivo geral do plano era o de não cometer os mesmos erros dos planos passados, assim, seria implantado de forma gradual e não existiriam congelamentos e sim uma "substituição natural" da moeda. O plano implementado por Fernando Henrique Cardoso, então Ministro da Fazenda, era composto originalmente por três fases: a primeira, que tinha como prioridade o ajuste fiscal que promovesse o equilíbrio das contas do governo, a fim de extinguir o componente inflacionário; a segunda se baseava na criação de um novo indexador intitulado Unidade Real de Valor (URV); e por fim, a terceira, que consistia na introdução de uma nova moeda e na sua estabilidade (transformação da URV em R\$).

Considerado um plano econômico bem sucedido, o Plano Real alcançou o seu objetivo de controlar a inflação, atingindo-a sem recessão e teve como marco a recuperação da credibilidade do país no plano internacional. O passar dos anos, como enfatiza Barros de Castro (2011, p. 160), porém, revelou que a vitória da inflação se limitou à estabilidade dos preços, mantendo a instabilidade no lado real da economia, com persistência da volatilidade do crescimento, baixos investimentos, sobretudo os de longo prazo de maturação, baixo 
desenvolvimento do mercado de crédito e permanência do viés curto-prazista dos ativos financeiros.

Os mais pobres são os que mais sofrem com a hiperinflação, pois não têm a mesma condição de repassar os aumentos de seus custos, como é feito pelos empresários, por exemplo. Quanto ao poder de compra, este se reduz cada vez mais até o momento em que tem seus salários reajustados, muitas vezes não tendo um aumento real, uma vez que o novo salário não representa o mesmo poder de compra para estes. Com a estabilidade da inflação, devido ao sucesso do Plano Real, houve um aumento de renda real média dos pobres e melhoria da distribuição de renda no país.

\section{Governo FHC (1995-2002)}

Ao assumir a presidência, Fernando Henrique Cardoso voltou suas atenções à economia brasileira a fim de organizar politicamente o país e diminuir os elevados índices de desempregos herdados dos governos anteriores. Assim, apesar da existência de crises externas que impactaram a economia do país durante o período, em virtude do seguimento das ações do Plano Real, a inflação se manteve baixa e assim permaneceu pelos anos seguintes.

A estabilidade de preços, adquirida com o plano real, resultou em perda das receitas inflacionárias que consistia em uma das fontes fundamentais de lucros dos bancos. Assim, uma opção para suprir esse déficit e elevar a receita era a expansão da carteira de crédito. Ainda assim, mesmo com o aumento do volume do crédito após a criação do Plano Real, a crise asiática que ocorreu em 1997 desacelerou o crescimento. No segundo governo FHC, gráfico 1, o saldo da carteira de crédito manteve-se no patamar de $27 \%$, ambiente que se alterou em 2002 chegando a $24 \%$ em relação ao PIB. 
GRÁFICO 1- Saldo da carteira de crédito fornecido para pessoas física e jurídica pelo setor bancário 1995/2002 - (Em \% do PIB)

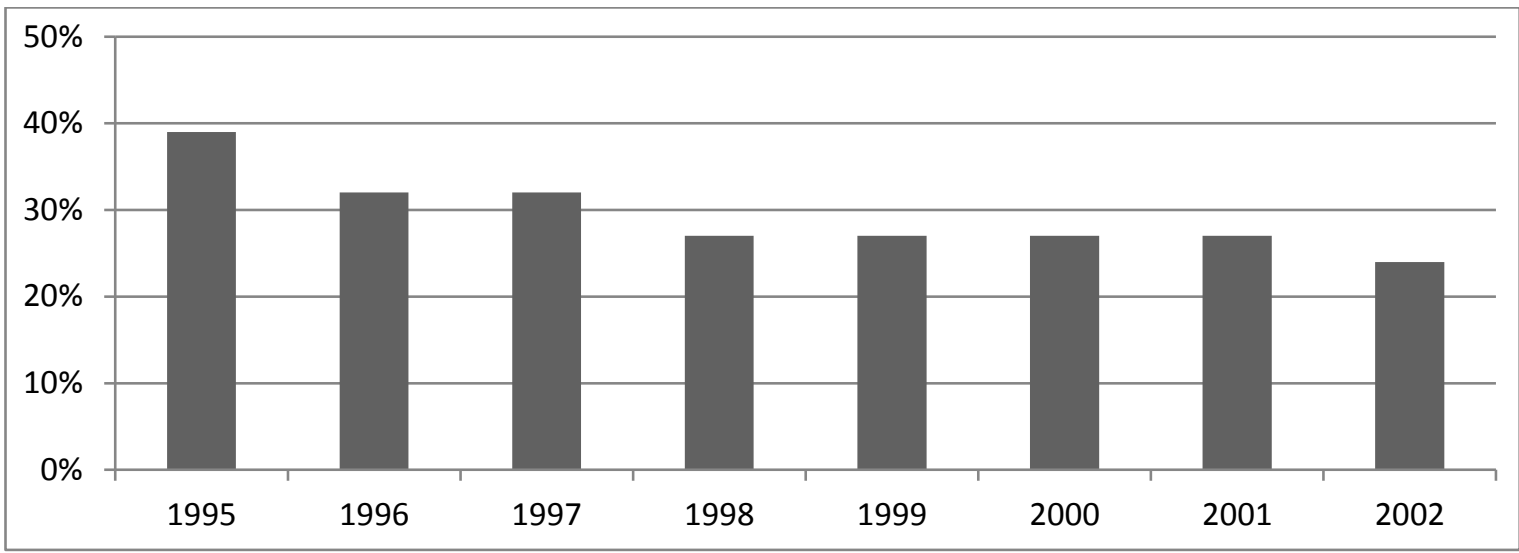

Fonte: Elaboração dos autores a partir de dados do Banco Central

A estabilidade de preços e o equilíbrio das taxas de inflação advindas do Plano Real, como pode ser notado no gráfico 2, favoreceram mais uma vitória nas urnas, levando FHC a seu segundo mandato que duraria até 2002. Assim, sendo o primeiro presidente reeleito consecutivamente, Fernando Henrique Cardoso iniciou o seu segundo governo objetivando primeiramente a redução da dívida pública.

GRÁFICO 2 - Taxa de inflação anual (aumento dos preços) 1995/2002-(Em \% a.a)

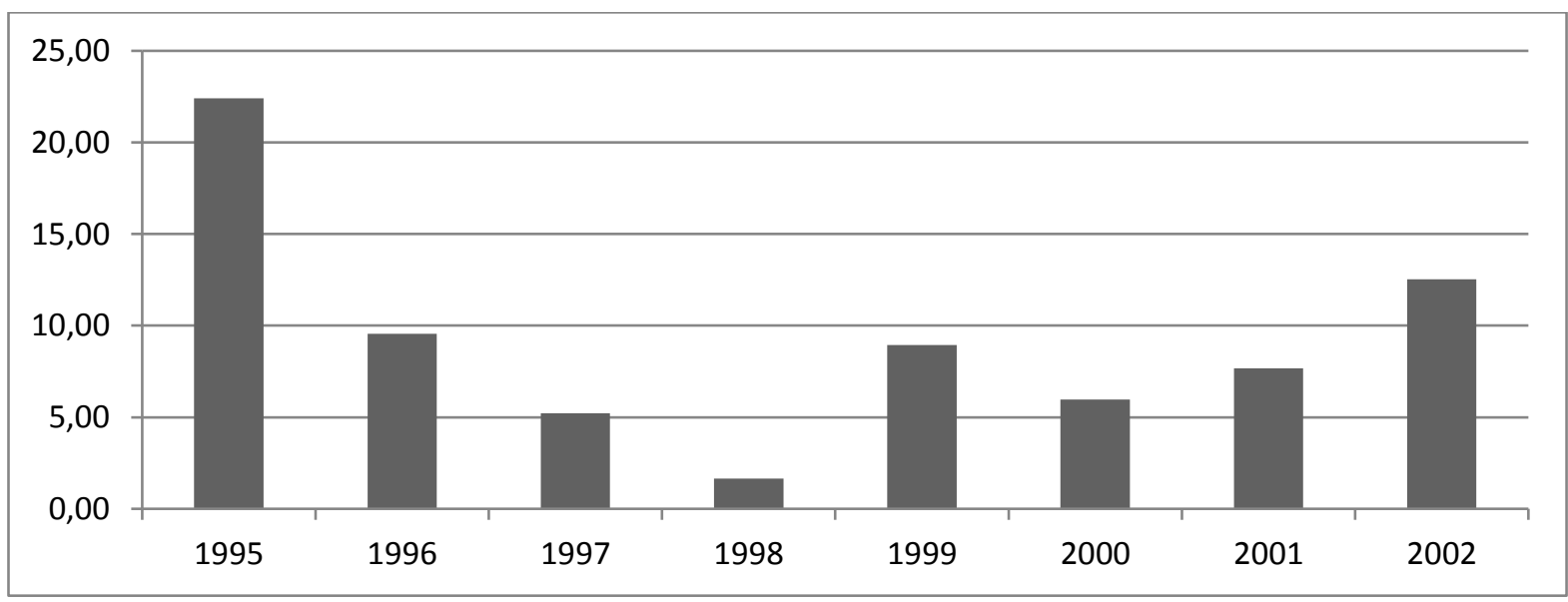

Fonte: Elaboração dos autores a partir de dados do IPEADATA

O baixo crescimento econômico do Brasil pode ser relacionado com alguns fatores, dentre eles o sistema de câmbio fixo utilizado pelo governo até 1999 que necessitava, caso ocorresse uma crise financeira externa, o aumento da taxa de juros. Esse sistema foi substituído pelo de câmbio flexível e pelo regime de metas de inflação (BARBOSA, p. 1, 2010). 
O gráfico 3 mostra que, após a adoção desse tipo de política econômica, o PIB brasileiro apresentou uma melhora, atingindo o nível de $4 \%$ no ano de 2000.

GRÁFICO 3 - Crescimento do PIB (crescimento da economia) 1995/2002 - (Em \% anual)

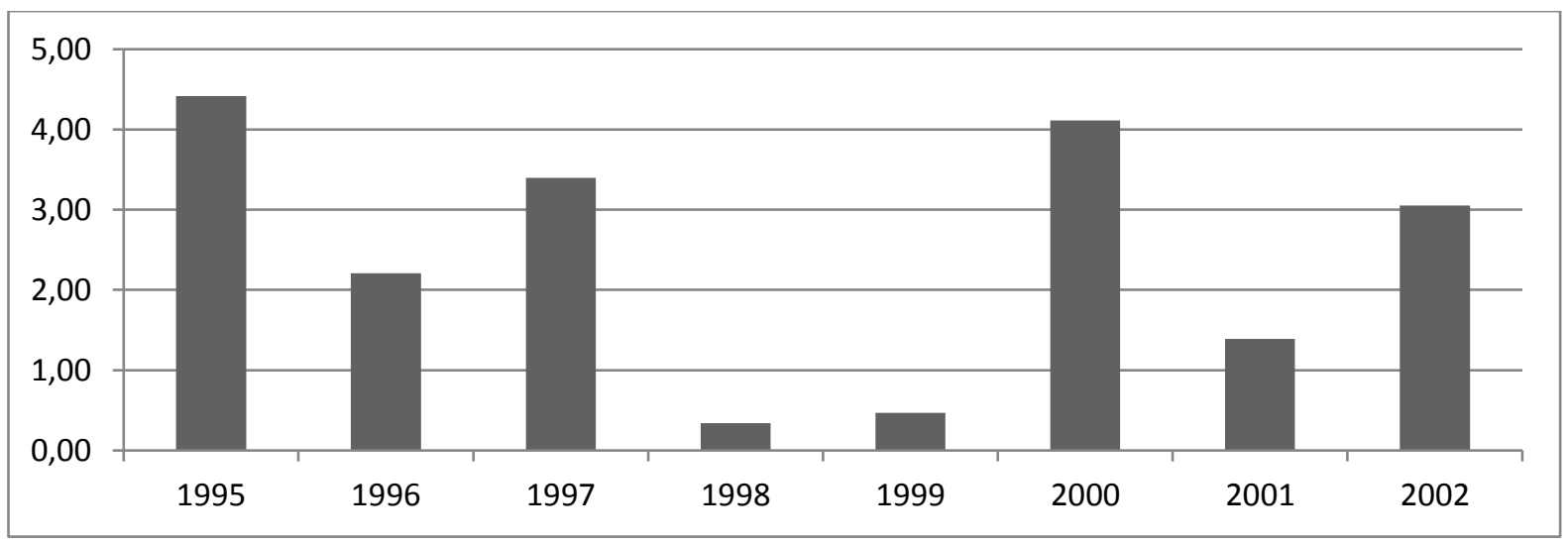

Fonte: Elaboração dos autores a partir de dados do THE WORLD BANK

Em 2001, a economia foi prejudicada por uma junção de fatores, dentre eles a crise de energia, o "contagio" argentino - que reduziu a entrada de capitais - e os atentados terroristas de 11 de setembro, que abalaram fortemente os mercados mundiais. Neste contexto, o risco-país voltou a aumentar, refletindo uma menor disponibilidade de capitais para o país e afetando os juros domésticos. Isso comprometeu o desempenho médio da economia no segundo Governo FHC (GIAMBIAGI, 2011, p. 180).

A expansão da oferta de crédito foi influenciada, principalmente, devido à expansão real da demanda no período. Segunda Cintra (2005, p. 294), tal expansão foi impulsionada pelo aumento de confiança na economia com a estabilidade do real, levando os consumidores, sobretudo os mais pobres, a aumentar a demanda por bens de consumo duráveis, em virtude do aumento real e a manutenção do poder aquisitivo.

Enfim, como é citado por Giambiagi (2011, p. 192), os dois governos do presidente Fernando Henrique foram bem distintos entre si quando levamos em consideração as políticas econômicas adotadas. Em contrapartida, ambos os mandatos tinham como principal objetivo o combate à inflação (GIAMBIAGI, 2011, p. 192). 
Governo Lula (2003-2010)

O primeiro Governo Lula foi caracterizado pela estabilidade (favorecendo o investimento e o crescimento do país), redução da dívida externa brasileira, e pela criação de políticas públicas para a erradicação da pobreza.

A seguir, no gráfico 4, pode-se considerar que o governo Lula, no geral, trouxe um significativo crescimento para o saldo das operações de crédito total, em grande parte devido às políticas econômicas adotadas, que favoreceram a expansão de financiamento para a população (GIAMBIAGI, 2011, p. 222).

GRÁFICO 4-Saldo da carteira de crédito para pessoas física e jurídica fornecido pelo sistema bancário 2003/2010 - (Em \% do PIB)

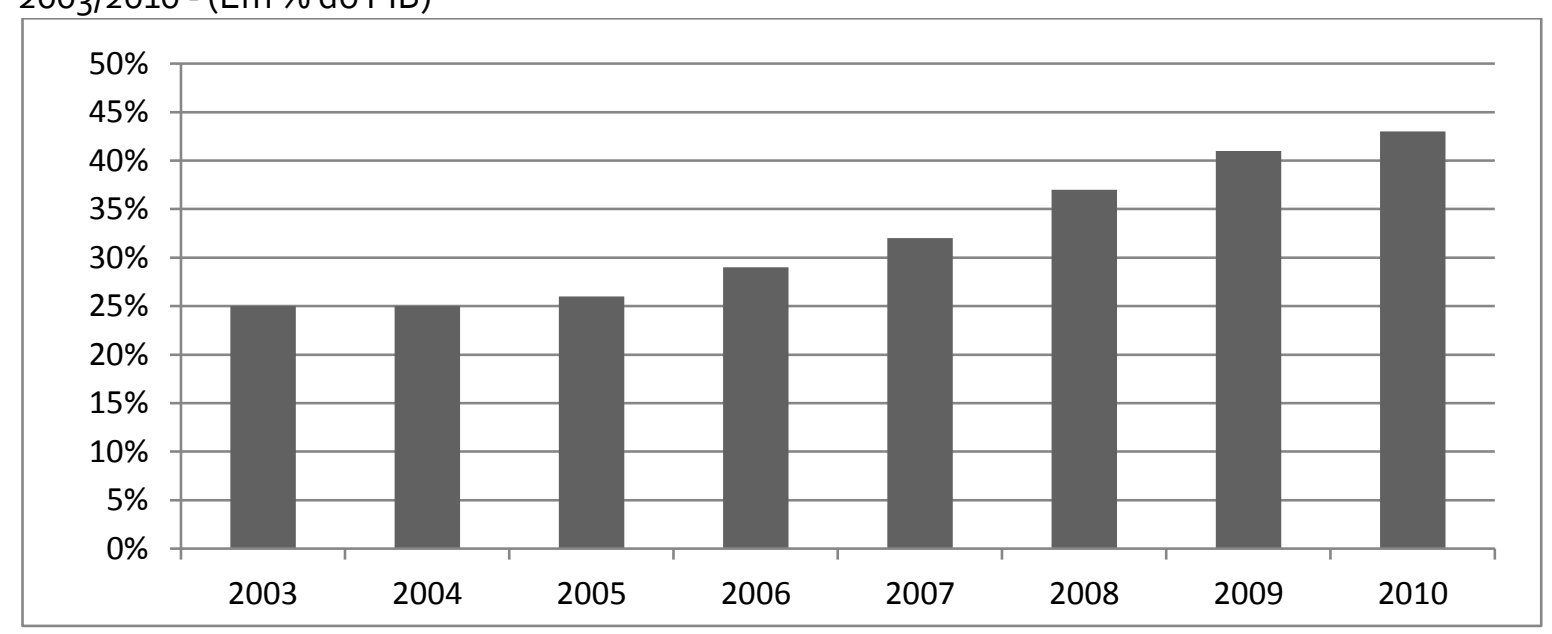

Fonte: elaboração dos autores a partir de dados do Banco Central.

O comportamento da economia brasileira, a partir de 2003, foi precisamente influenciado pelo desenvolvimento da economia internacional e, paralelamente à continuidade do regime de metas de inflação, da taxa de câmbio e da inflação. O governo Lula foi marcado por um aumento do produto com estabilidade de preços e progressos consideráveis na distribuição da renda e contenção da miséria. Ou seja, o conjunto de fatores para um processo de desenvolvimento se fazia presente (CURADO, 2011, p. 102).

No ambiente da economia real, após o efeito inicial da alta dos juros que ocorreu em 2003, O PIB teve um crescimento moderado, de apenas 1,1\%. Entretanto, nos anos posteriores (gráfico 5), a economia brasileira apresentou uma atividade maior - tudo isso acompanhando o significativo crescimento da economia mundial. Tão somente no final de 2008 tal crescimento seria retido pela crise mundial, mas, como será observado adiante, em 
2010, retorna com força. No geral, a taxa média do crescimento do PIB nos anos 2003-2010 foi de $4,0 \%$, o resultado seria mais favorável não levando em consideração as baixas taxas de 2003 e 2009 .

GRÁFICO 5 - Crescimento do PIB (crescimento da economia) 2003/2010- (Em \% anual)

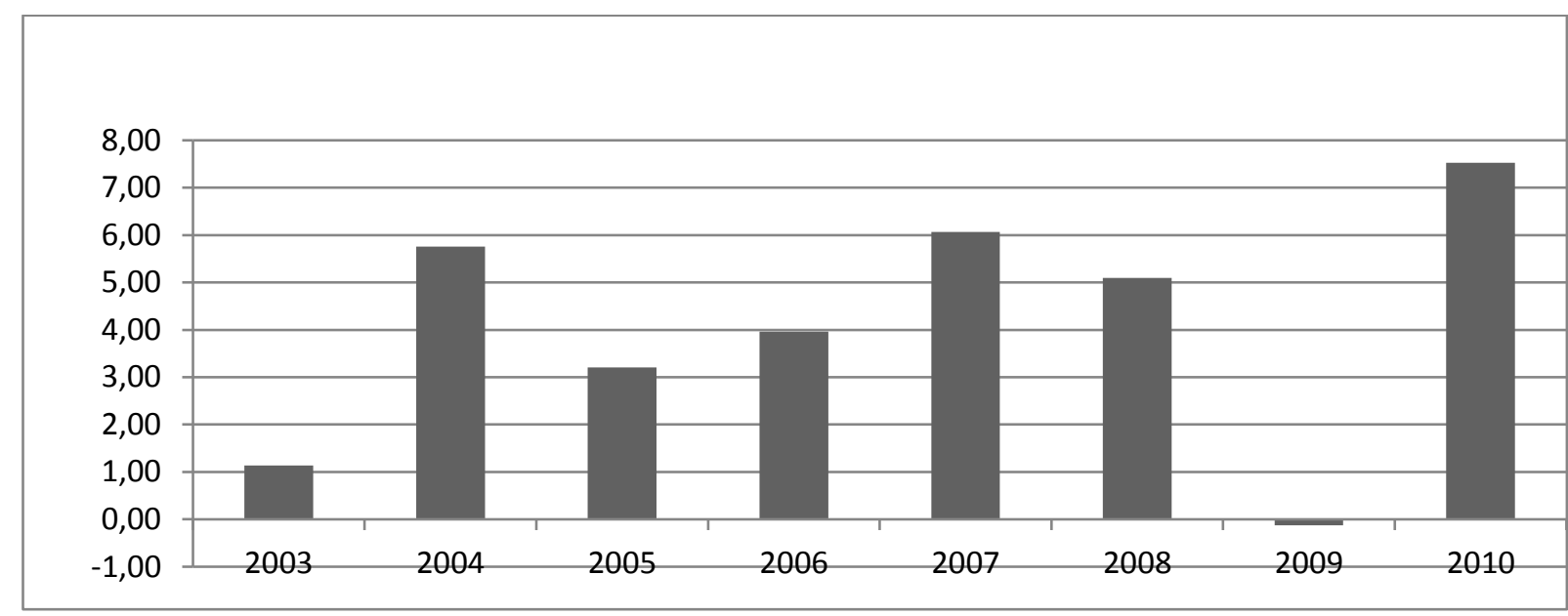

Fonte: elaboração dos autores a partir de dados do The World Bank.

Adicionalmente no gráfico 6, a inflação manteve-se sempre no intervalo de tolerância definido pelo sistema de metas de inflação, e mostrou uma trajetória cadente quando comparada às taxas médias observadas em outros governos. Ao mesmo tempo, o maior otimismo com a evolução futura da economia causou uma intensificação da demanda por emprego, gerando uma queda importante das taxas de desemprego, acompanhada de uma importante elevação dos níveis de formalização da economia (GIAMBIAGI, 2011, p. 218).

GRÁFICO 6 - Taxa de inflação (aumento dos preços) 2003/2010 - (Em \% anual)

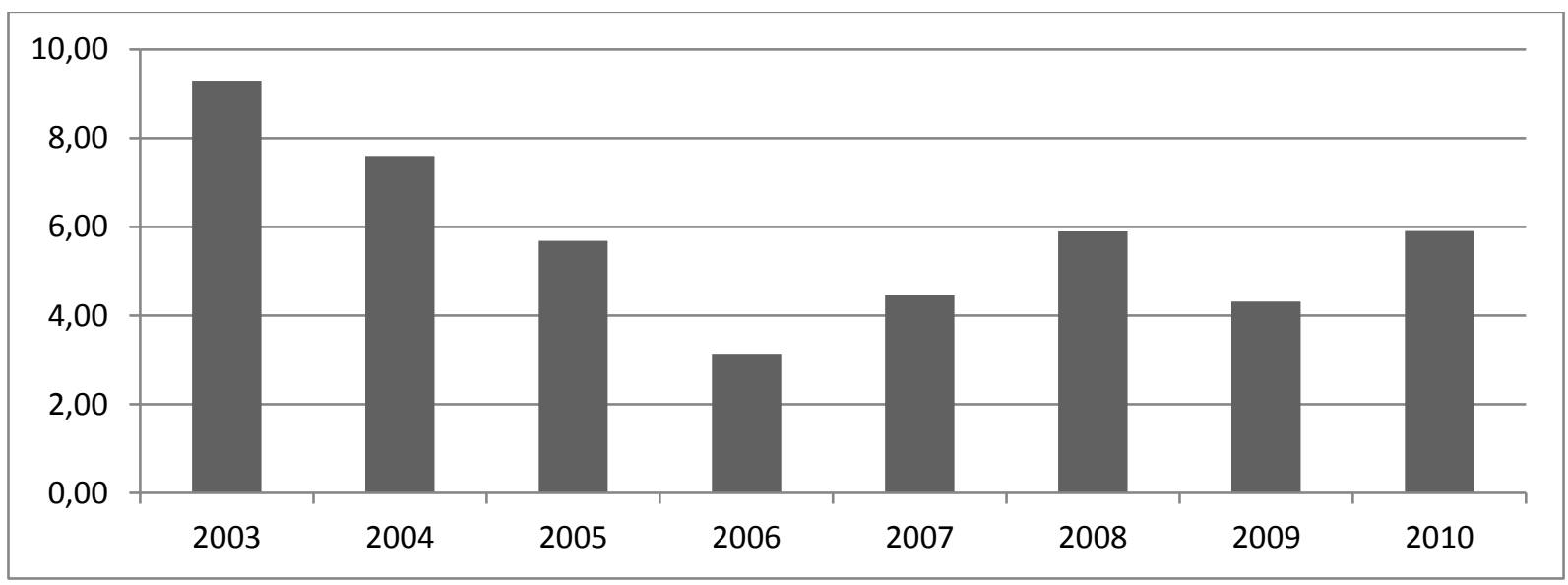

Fonte: elaboração dos autores a partir de dados do IPEADATA. 
O aumento da renda real associado aos incrementos de recursos nos programas sociais e crescente aumento do emprego, no cenário de uma economia em ascensão, com inflação relativamente controlada e melhora na distribuição de renda, explica o porquê de Lula ter conseguido deixar o poder com uma das maiores aprovações da história, além de ter conseguido eleger sua candidata Dilma Rousseff para a presidência (GIAMBIAGI, 2011, p. 231).

Primeiro governo Dilma (2011-2014)

Lançando no início do governo o Brasil Sem Miséria, o governo estava determinado a incentivar o crescimento com melhor distribuição de renda, diminuindo as desigualdades e estimulando a inclusão social. A maior mudança decorrente deste programa foi o Brasil Carinhoso, uma estratégia a fim de desenvolver iniciativas de educação, saúde e renda. No quesito renda, este propiciou um benefício com valor que mudava de acordo com o grau da pobreza, assim, quanto menor a renda, maior o montante pago pelo Bolsa Família, garantindo que os usuários saíssem do nível de renda da extrema pobreza (CAMPELLO, 2013, p. 22,).

Campello (2013, p. 22) enfatiza que o Brasil Carinhoso, de início, tinha como alvo crianças e adolescentes, cujo o grau de extrema pobreza era muito elevado. Posteriormente foram ampliados a todos os beneficiários do Bolsa Família. Esta alteração foi fundamental para a instituição de um mínimo de renda abaixo do qual não seria aceitável que nenhum cidadão se encontrasse. Diante disso, milhões de brasileiros saíram da extrema pobreza.

Juntamente com a estratégia gradualista de combate à inflação, houve a adoção de uma série de medidas no ambiente de crédito, câmbio e fiscal. Em 2011, foram adotadas medidas de restrição de crédito ao consumo e de controle dos fluxos de capitais, além de estabelecer limites às operações especulativas de investidores estrangeiros com derivativos cambiais e medidas adicionais de austeridade fiscal (CAGNIN et al, 2013, p. 172). Paralelamente, o governo incentivou os bancos públicos a realizar políticas anticíclicas, a fim de neutralizar a desaceleração do crédito pelos bancos privados, como verificado no gráfico 7 a seguir. 
GRÁFICO 7-Saldo da carteira de crédito para pessoas física e jurídica pelo sistema bancário 2011/2014 - (Em \% do PIB)

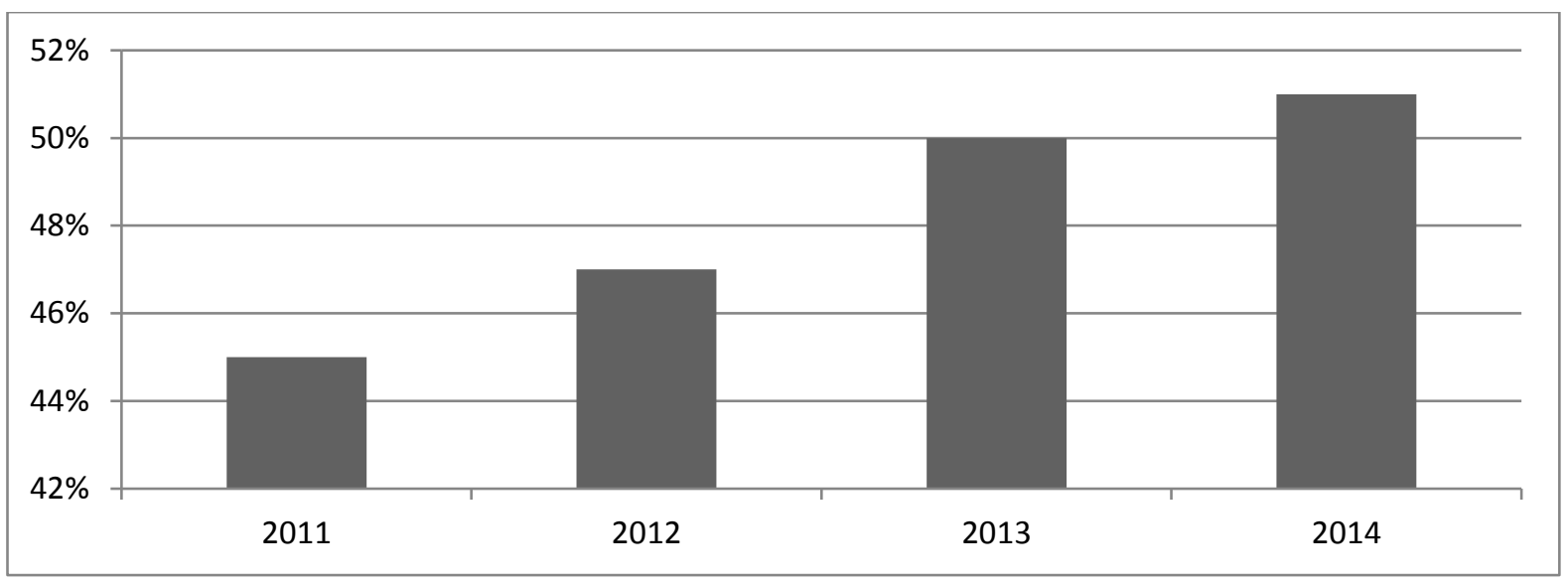

Fonte: elaboração dos autores a partir de dados do Banco Central.

Desde o governo anterior a economia brasileira começou a experimentar um novo regime de crescimento, induzido pela demanda, onde as políticas de distribuição de renda e o crescimento do mercado interno, juntamente com a entrada das famílias antes excluídas do consumo de massas, tiveram um papel essencial - principalmente entre os anos de $2010 \mathrm{e}$ 2011 o crescimento com base no mercado interno e na redistribuição de renda foi evidente (TEIXEIRA; PINTO, 2012, p. 935).

Uma fragilidade persistente da economia brasileira ao longo dos últimos anos foi a persistência da inflação em ficar acima da meta, embora nos limites das bandas determinadas pelo COPOM. O princípio sobre a inflação brasileira, de acordo com Contri (2014, p. 14), é que ela se baseia nos ajustes estruturais pelos quais o país veio passando nos últimos anos, como mencionado anteriormente; apenas em 2006, 2007 e 2009 a inflação conseguiu "respeitar" a meta, ficando abaixo de 4,5\%. Como mostra o gráfico 8 a seguir: 
GRÁFICO 8 - Taxa de inflação (aumento dos preços) 2011/2014- (Em \% a.a)

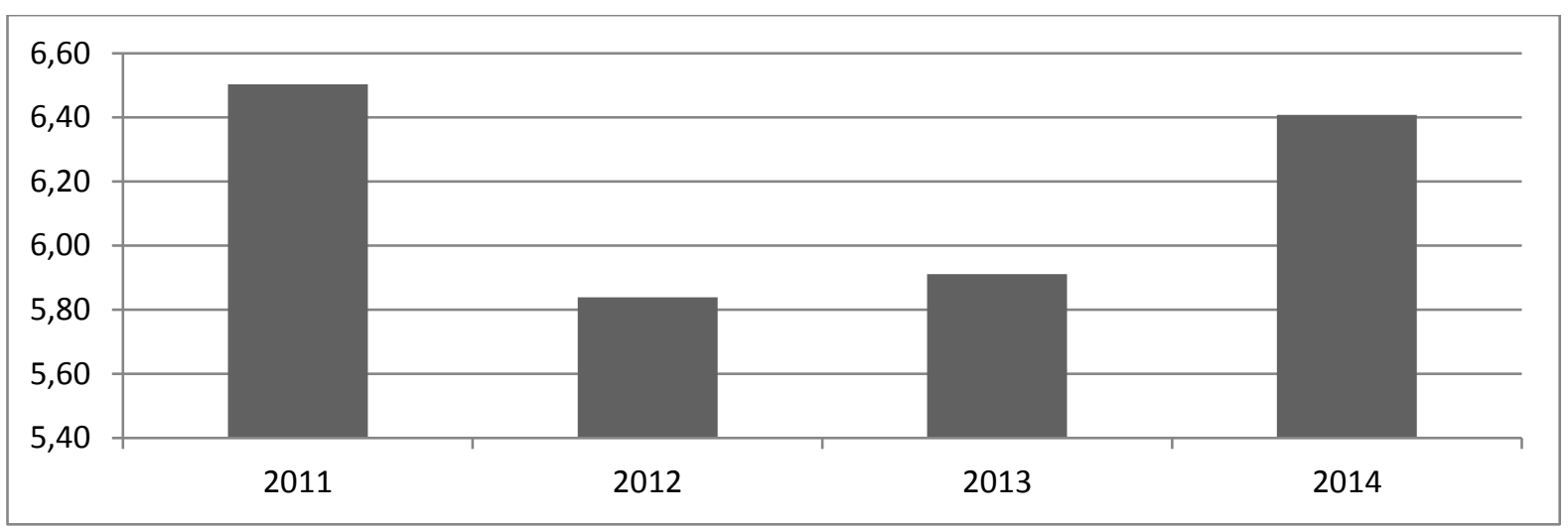

Fonte: elaboração dos autores a partir de dados do IPEADATA.

O governo Dilma não obteve resultados satisfatórios quanto ao crescimento do PIB. Como é apresentado no gráfico 9, de fato, depois de uma rápida recuperação apresentada em 2010 (7,53\%), as taxas de crescimento reduziram-se para 3,97\% e 1,92\%nos anos posteriores.

GRÁFICO 9 - Crescimento do PIB (crescimento da economia) 2011/2014- (Em \% anual)

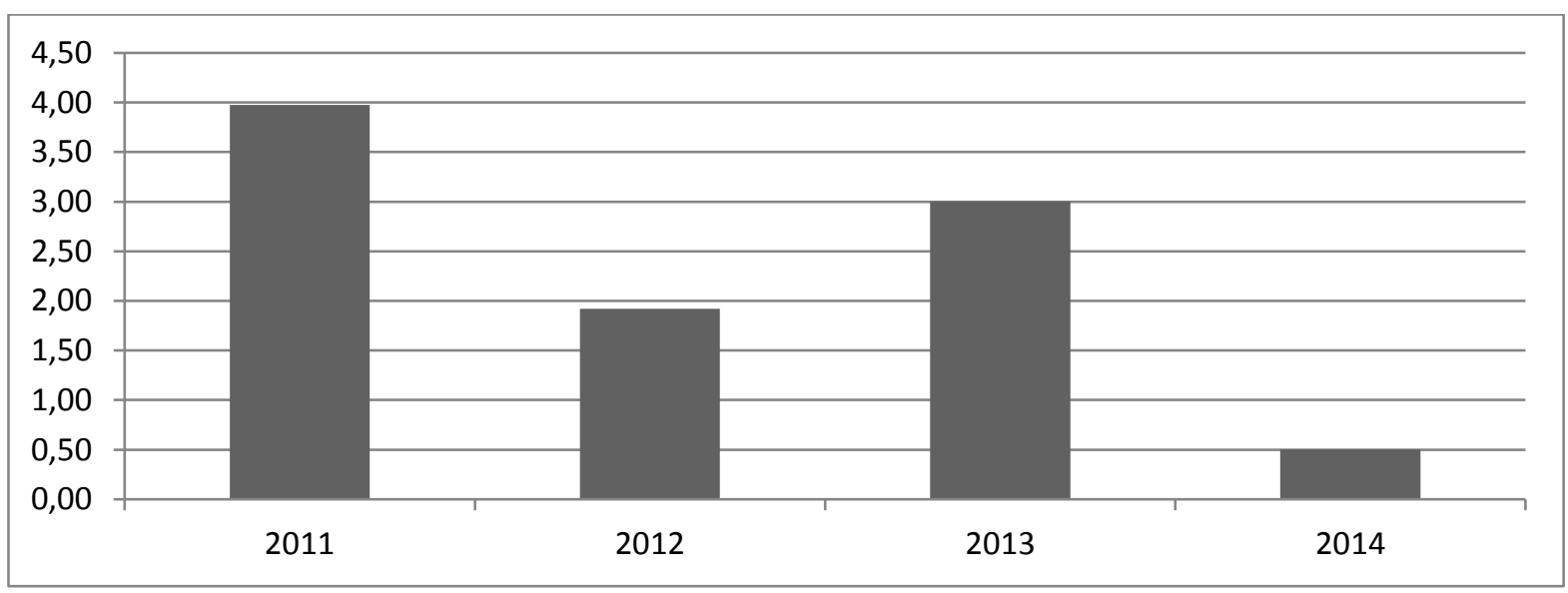

Fonte: elaboração dos autores a partir de dados do THE WORLD BANK.

Contri (2014, p. 12) expõe que entre os fatores determinantes desse desempenho, destaca-se a desaceleração do crescimento do consumo das famílias, o qual havia sido estimulado nos anos anteriores, mas parece ter encontrado seu limite de crescimento na sua própria capacidade de endividamento, na restrição maior ao crédito, bem como no aumento das taxas de juros ocorrido em 2013; e, associado a isso, houve uma desaceleração nos investimentos, a partir de 2011. 
Enfim, não podemos deixar de mencionar que um dos pontos mais criticados do governo Dilma foram as baixas taxas de crescimento do PIB (CONTRI, 2014, p. 11). A relação crédito/PIB apresentou uma expansão ao longo dos anos e alguns fatores contribuíram para isso, como a retomada do setor formal de trabalho e aumento da remuneração do trabalho, decorrente, principalmente, das políticas de valorização do salário mínimo (DIEESE, 2014, p. 23). Ainda, segundo o estudo realizado pela DIEESE (2014, p. 28), a expansão do crédito também foi favorecida pela política econômica voltada para esse fim, incentivada pelos bancos públicos federais e pelo BNDES, com o intuito de enfrentar a crise econômica mundial.

Desigualdade de renda (1995-2014)

É notório que entre as mudanças pelas quais o Brasil vem passando nas últimas décadas, uma das mais importantes foi a redução da concentração de renda. A partir de 2001, seja qual for a medida de desigualdade levada em consideração será notado uma queda contínua e acentuada. O coeficiente de Gini, por exemplo, mostra uma desconcentração de renda no período que teve expressivos resultados sobre a pobreza e a pobreza extrema no país. Mas apesar dos diversos fatores responsáveis por essa redução, o Brasil se encontra entre os países mais desiguais do mundo (BARROS et al, 2006, p. 15).

Entre os anos de 1995 a 2002, o Índice de Gini, importante indicador de mensuração da concentração de renda do país, sofreu poucas variações consideráveis, mesmo voltando a atenção para o crescimento do PIB em 3,38\% em 1997, o índice permaneceu em o,60. Ou seja, apesar do crescimento econômico neste período, não houve redução relevante da desigualdade social (gráfico 10).

GRÁFICO 10 - Desigualdade de Renda - Coeficiente de Gini 1995/2014 - (Em \%)

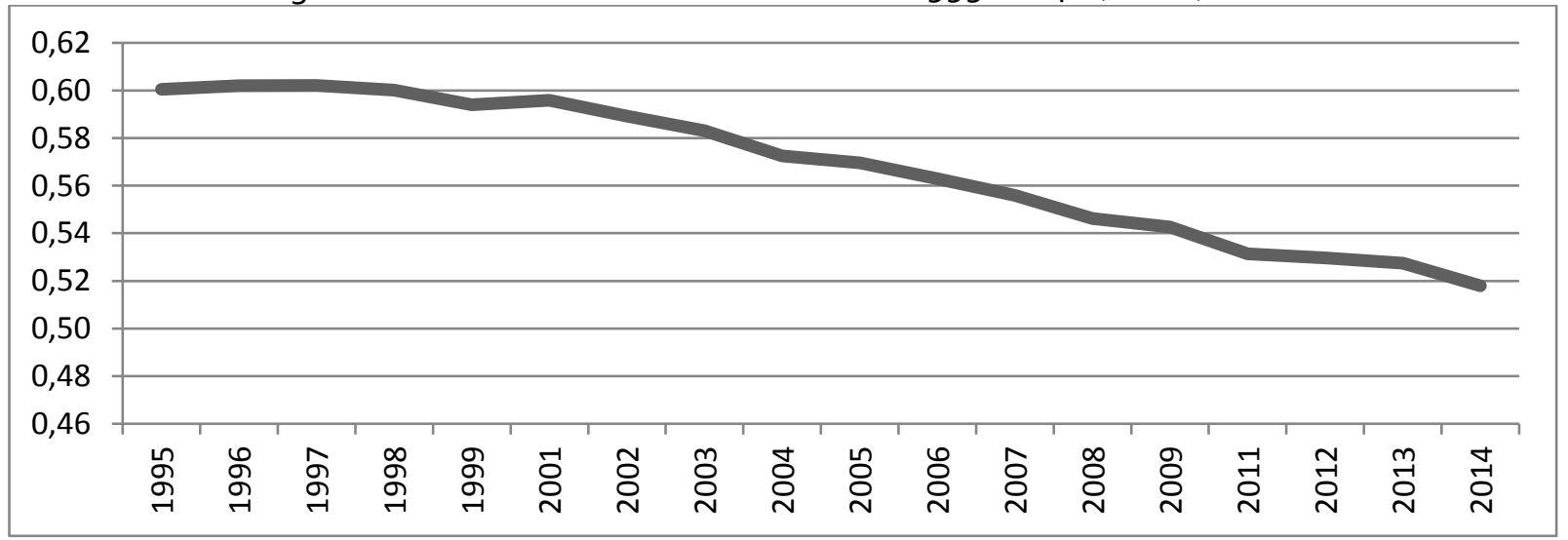

Fonte: elaboração dos autores a partir de dados do IPEADATA. 
Já no período do governo Lula, houve uma expressiva redução da concentração de renda no país, impactando no percentual do índice da renda detida pelos $10 \%$ mais ricos que variou de 47,3\% em 2001 para 42,45\% em 2009, permanecendo em declínio nos anos posteriores como observado no gráfico 11 a seguir:

GRÁFICO 11 - Participação de renda detida pelos 10\% mais ricos (montante da renda nacional mantida pelos $10 \%$ mais ricos) - (Em \% anual)

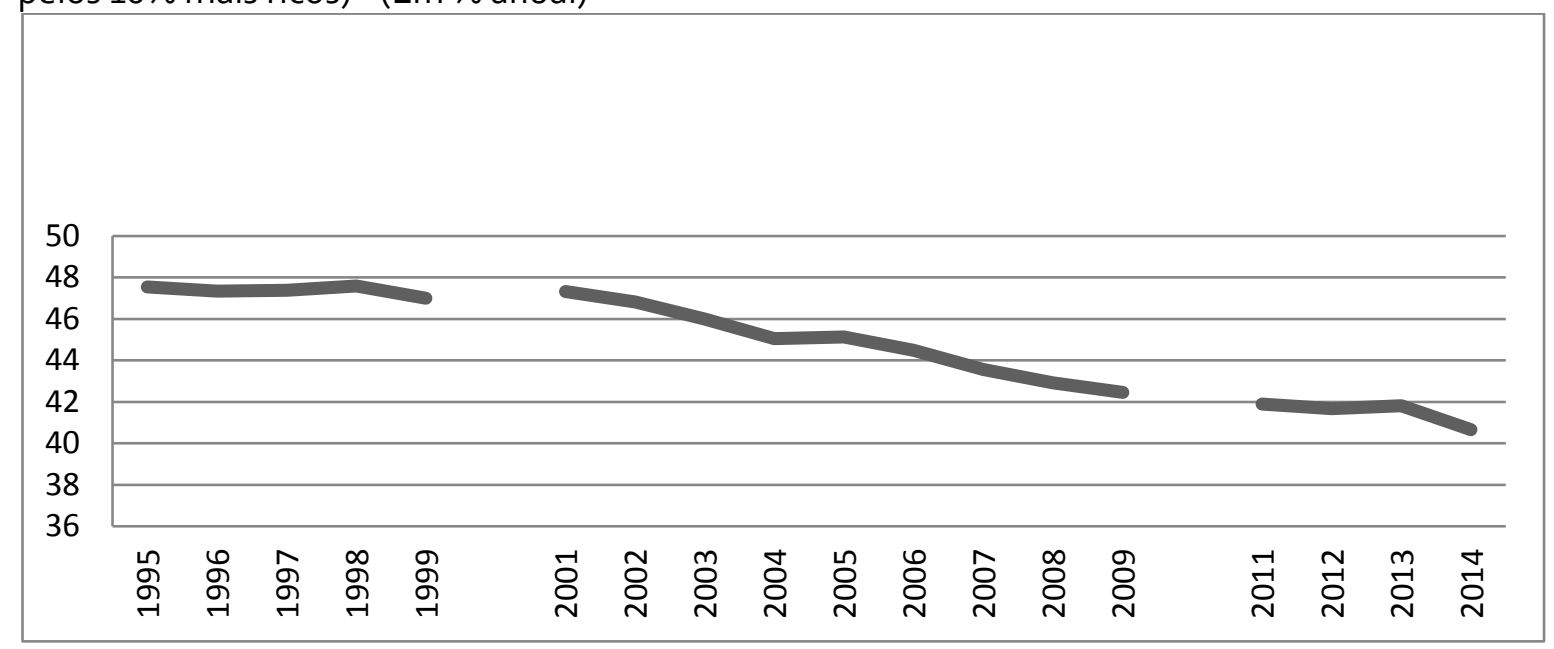

* Dados indisponíveis para os anos 2000 e 2010.

Fonte: elaboração dos autores a partir de dados do The World Bank.

Quanto ao total de renda apropriado pelo grupo dos 10\% mais pobres, é notado pelo gráfico 12 cuja a variação foi de 0,71\% para 0,99\% no período em questão. Apesar do declínio da participação de renda detida pelos indivíduos que compõem a parcela dos 10\% mais pobres nos anos de 2010, 2011 e 2013, a evolução é plausível.

GRÁFICO 12 - Participação de renda detida pelos $10 \%$ mais pobres (Em \%)

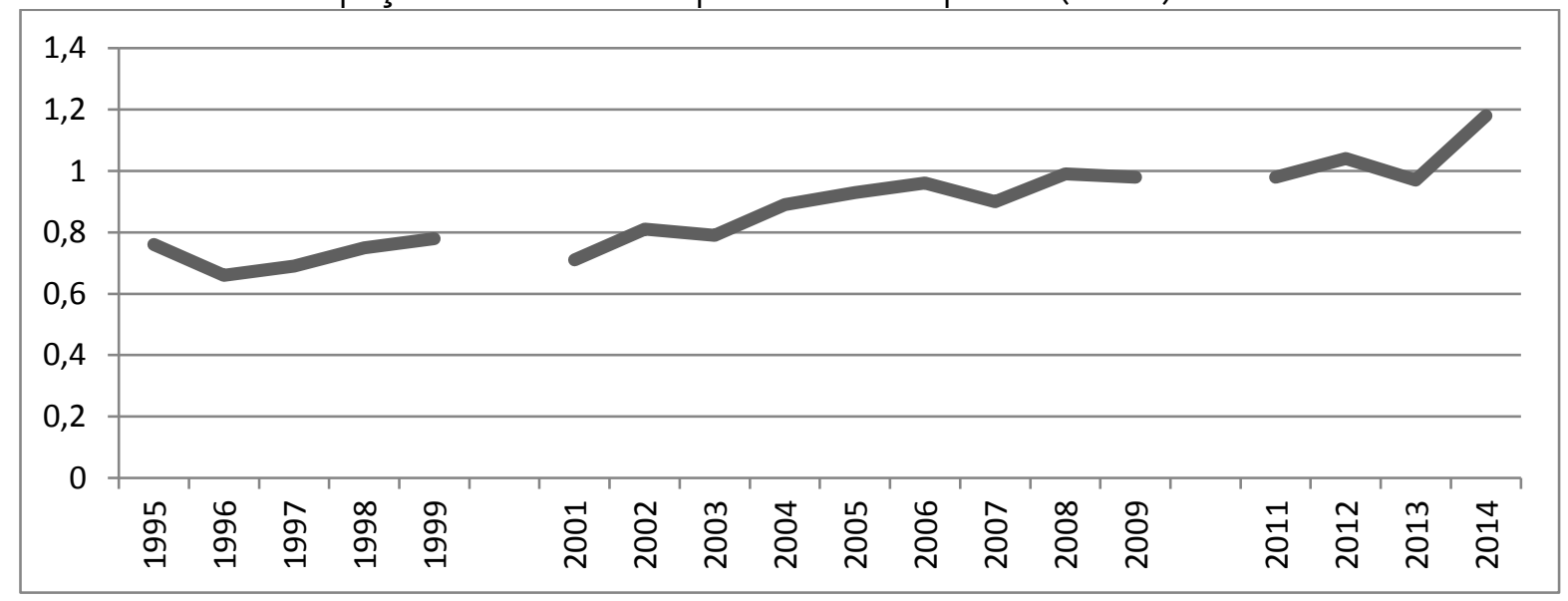

* Dados indisponíveis para os anos 2000 e 2010.

Fonte: elaboração dos autores a partir de dados do THE WORLD BANK. 
Enfim, os indicadores da desigualdade obtiveram uma significativa melhora. Entretanto, vale a pena destacar que, mesmo com os avanços - como a melhora do Índice de Gini - a concentração de renda no país é excepcionalmente elevada, enquadrando o Brasil entre os países mais desiguais do mundo.

Atualmente, o crédito vem tomando importante papel na expansão do consumo. De acordo com Joseph Stiglitz há tempos que o dinheiro desempenha um papel fundamental nas perspectivas gerais sobre a economia e sobre a vida de uma forma mais ampla. Ele enfatiza que "o dinheiro faz o mundo girar e o crédito detém a força econômica, onde nos tempos de hoje a maioria das transações comerciais não tem nada a ver com a moeda e sim com o crédito, o crédito determina os rumos da economia" (VALOR, 2004, p. C12).

Durante o governo Lula, o crédito obteve um aumento expressivo e contínuo, mesmo após a crise de 2008. Posteriormente, com o cenário macroeconômico favorável, uma maior dinamização do crédito favorecia a expansão dos gastos refletindo sobre o consumo e o investimento. Portanto, o aumento do crédito colaborou para um ciclo favorável na economia do país (MORA, 2015, p. 7).

\section{Desenvolvimento financeiro e desigualdade de renda}

O Brasil, um país com um grande percentual de pobres e um dos mais desiguais, considerando a distribuição de renda, possui um sistema financeiro heterogêneo e com um elevado grau de concentração, no qual uma quantidade significativa da população ainda é excluída, em particular, na obtenção de crédito (BEMERGUY; LUPORINI, 2006, p. 4).

Segundo Bittencourt et al (2005, p. 203), a partir do início do governo Lula, tal situação veio modificando-se gradativamente, devido a políticas direcionadas à oferta de crédito para os mais pobres.

Atualmente, a desproporção na distribuição de renda no Brasil tem sido muito estudada. Barros et al (2000, p. 6) inferem, por exemplo, que a pobreza no Brasil originou-se na desigualdade de renda e riqueza e assim o argumento quanto à essência da pobreza estava relacionado à questão sobre a natureza distributiva de rendimentos.

Como mencionado anteriormente, o Brasil se destaca entre os países com os coeficientes de concentração de renda mais elevados. O índice de Gini brasileiro permaneceu 
em média 0,6o nos últimos anos e, em contrapartida, a média latino-americana vem sendo em média 0,50 (RAMOS; VIREIRA, 2001, p. 6).

Regionalmente, o Norte e o Nordeste concentram uma maior parcela da população de baixa renda. E é justamente essa desigualdade entre as regiões do país que reflete a desigualdade na distribuição de renda e é a mesma desigualdade que se faz evidente nas particularidades de acesso aos diversos serviços financeiros. Ou seja, mesmo tendo o maior sistema financeiro da América Latina (D'ÁVILA, 2017, p. 1), o Brasil possui uma grande discrepância no tocante às regiões no fornecimento de serviços bancários.

Por fim, os estudos mais recentes percebem que, no aumento do acesso a serviços bancários destinados à população mais pobre, há um amparo contra fases de baixa renda e oscilações inesperadas de renda e consumo (BEMERGUY; LUPORINI, 2006, p. 8). Além do mais, isto vem como opção de possibilidades de investimentos e, assim, promover o crescimento da renda da população mais carente. Desse modo, há indícios de um papel relevante do sistema financeiro no combate à desigualdade de renda.

\section{Estudo econométrico}

\section{Discussão de trabalhos}

Na literatura, alguns trabalhos discorrem sobre o impacto da moeda e do sistema financeiro como meio para a redução da desigualdade de renda no Brasil, como os de Rodrigues e Sabbadini (2010), Abitante (2007) e Bittencourt (2006), que relacionam a inflação, o mercado de crédito e o desenvolvimento financeiro com a desigualdade.

No trabalho de Rodrigues e Sabbadini (2010, p. 11) foi analisado como uma alteração da taxa de inflação seria capaz de influenciar o índice de gini. O trabalho foi estruturado com dados em painel com aproximadamente 80 países e informações anuais no período de 19872006. Modelos estáticos e dinâmicos foram estimados com o fundamento no qual a desigualdade de renda é explicada pela inflação, sempre monitorando a presença de efeitos fixos para países e anos. Nas primeiras estimações, utilizando modelos lineares, não obtiveram relação positiva entre a distribuição de renda e a inflação. Posteriormente, os autores flexibilizaram as formas funcionais, sendo possível constatar uma correlação positiva do Índice de Preços ao Consumidor (IPC) sobre o gini - assumindo a existência de outliers. Os resultados indicaram que uma elevação no IPC de zero para 10 pontos percentuais ao ano 
aumentaria o índice de gini, levando em conta uma escala de zero a 100, em, no máximo, 0,05 pontos percentuais.

Abitante (2007, p. 165) argumentou, em seu trabalho, as variáveis que influenciavam a taxa de crescimento da renda per capita nas unidades federativas do Brasil tendo como base os anos de 1995 a 2002, e com dados em painel, assim como se há indício de convergência na taxa de crescimento da renda per capita das unidades. Os resultados apresentaram sinais de convergência na taxa de crescimento da renda per capita no Brasil. Ademais, a quantidade de crédito bancário e o investimento governamental se revelaram estatisticamente significantes na interpretação do crescimento da renda per capita das unidades federativas.

Bittencourt (2006, p. 15) examinou a importância do desenvolvimento financeiro na desigualdade de renda no Brasil nos anos de 1980 a 1990. A metodologia envolveu dados em painel. Os resultados apontaram que mais acesso ao sistema financeiro e ao crédito possibilitou uma significativa redução da desigualdade de renda durante o período analisado. Ainda assim, a ampla variação de resultados apresentados ao longo do estudo confirma a previsão teórica, segundo o autor, que mais mercados de acesso ao crédito, principalmente para os mais pobres e quando direcionados a um nível individual, tem um impacto favorável na redução da desigualdade dos mais pobres sem afetar a eficiência econômica do país. Tais conclusões reforçam o papel do desenvolvimento financeiro para a diminuição da desigualdade.

Desse modo, os trabalhos mencionados mostram a importância que alterações na taxa de inflação, maior acesso ao mercado de crédito pelos pobres e o desenvolvimento financeiro pode trazer para a equidade de renda e, consequentemente, redução da desigualdade.

\section{Metodologia}

O modelo a ser estimado nesse artigo é o de Mínimos Quadrados Ordinários (MQO) em regressões múltiplas através do software Stata. O MOO é um dos métodos mais usados para análise de regressão, sobretudo porque é intuitivamente preciso e matematicamente mais simples quando comparado a outros métodos. O MQO permite que a reta de regressão estimada passe na mesma distância entre os pontos dos dados observados (GUJARATI; PORTER, 2011). 
Para encontrarmos os estimadores de $\mathrm{MQO}$, levamos em consideração a função de regressão amostral (FRA) equivalente à função de regressão populacional (FRP), que é:

$Y_{i}=\hat{\beta}_{1}+\hat{\beta}_{2} X_{2 i}+\hat{\beta}_{3} X_{3 i}+\widehat{u_{\imath}}$

onde $Y_{i}$ é o estimador de $\mathrm{E}\left(\mathrm{Y} / X_{i}\right), \hat{\beta}_{1}, \hat{\beta}_{2}$ e $\hat{\beta}_{3}$ são os estimadores de $\beta_{1}$, $\beta_{2}$ e $\beta_{3}$, respectivamente, $X_{i}$ é o i-ésino nível da variável independente $X(\mathrm{i}=1,2, \ldots, \mathrm{n})$, e por fim, $\widehat{u_{l}}$ é o termo residual, a contrapartida amostral do termo de erro estocástico $u_{i}$. Ademais, o procedimento de MOO se baseia na escolha dos valores dos parâmetros desconhecidos de maneira que a soma dos quadrados dos resíduos (SOR) seja a menor possível.

$\min \sum \hat{u}_{i_{i}}^{2}=\sum\left(Y_{i}-\hat{\beta}_{i}-\hat{\beta}_{2} X_{2 i}-\hat{\beta}_{3} X_{3 i}\right)^{2}$

Em que a expressão da SQR é obtida por simples manipulação algébrica da equação (1). A fim de obter os estimadores que minimizem a equação (2), o mais indicado seria derivar em relação à incógnita $(\beta)$, igualar a zero as expressões resultantes e resolvê-las simultaneamente.

Ou seja, o MQO é muito utilizado por se tratar de uma técnica de otimização matemática que tem por finalidade tentar identificar o melhor ajustamento para um conjunto de dados, com o intuito de minimizar a soma dos quadrados das diferenças entre o valor estimado e os dados observados (GUJARATI; PORTER, 2011).

Sendo assim, o período de estudo a ser analisado compreende os anos de 1995 a 2014 a fim de captar a relação da desigualdade com algumas variáveis consideradas importantes, pela literatura, para entender esse processo.

\section{Dados}

A regressão constitui uma amostra de dados anuais, do ano de 1995 a 2014 do Brasil. A tabela 1 a seguir apresenta a descrição dos dados que foram utilizados para cada variável do modelo. Os dados do índice de Gini, importante indicador da concentração de renda do país e os dados do Índice de Preços ao Consumidor Amplo, foram obtidos no IPEADATA (2017). A variável credit, que constitui o saldo da carteira de crédito em relação ao PIB, foi retirada do Banco Central (2017). Por fim, os dados do crescimento do PIB (gdp/br), em porcentagem, foram obtidos do The World Bank (2017). 
Tabela 1-Variáveis e descrição

\begin{tabular}{lll}
\hline Variáveis & Descrição \\
\hline & gini & Índice de Gini \\
credit & Saldo da carteira de crédito em relação ao PIB \\
gdp $/ b r$ & Produto Interno Bruto \\
inflacp & Índice de Preços ao Consumidor Amplo \\
\hline
\end{tabular}

Fonte: elaboração dos autores.

A representação do modelo é especificado pela seguinte equação:

gini $=\beta_{0}+\beta_{1}$ credit $+\beta_{2} g d p / b r+\beta_{3}$ inflacp $+u$

Onde os $\beta$ 's são os coeficientes a serem estimados e v é o erro do modelo.

Ademais, para que a parcela dos mais pobres se reduza, a renda dos mesmos deve aumentar e, para isso, é indispensável que haja crescimento econômico ou reduções no grau de desigualdade (BARROS et al, 2006, p. 31).

Assim como no trabalho de Rodrigues e Sabbadini (2010), este trabalho tenta avaliar o impacto da taxa de inflação sobre a distribuição de renda de um país. De acordo com os autores, diversos debates econômicos relatam os males que as elevadas taxas de inflação causam aos mais pobres. O efeito da desigualdade teria origem do acesso diferenciado a ativos financeiros presentes entre ricos e pobres. À vista disso, os mais privilegiados teriam melhores condições de se protegerem com uma inflação elevada, ao contrário dos mais pobres. Dessa forma, a inflação destinaria ao crescimento da desigualdade de renda, o que seria mais um motivo para a permanência da mesma em níveis mais baixos (RODRIGUES; SABBADINI, 2010, p. 2).

Segundo um estudo realizado pelo Dieese (2014, p. 2), o crédito possui um papel fundamental na economia, visto que é crucial ao financiamento do consumo das famílias e do investimento dos setores produtivos. Ademais, um dos fatores que evidenciam o crescimento da economia do país no período recente é, justamente, a expansão do mercado de crédito (DIEESE, 2014, p. 2). 
Resultados

Levando em consideração o modelo a seguir, podemos verificar na tabela 2, que o Produto Interno Bruto ( $g d p / b r)$ não é estatisticamente significativo. O saldo da carteira de crédito em relação ao PIB (credit)apresentou sinal negativo. Já o Índice de Preços ao Consumidor Amplo (inflacp)apresentou o coeficiente estimado positivo. Sendo assim, há evidências de que o saldo da carteira de crédito em relação ao PIB e o Índice de Preços ao Consumidor Amplo estão relacionados com o Índice de Gini. O $R^{2}$ indica que aproximadamente $74 \%$ da variação do gini pode ser explicada pelas variáveis atribuídas ao modelo.

Tabela 2 - Resultados da regressão para gini ${ }^{1}$

\begin{tabular}{clllll}
\hline Variáveis & Coeficientes & Teste-T & P-valor & Regressão Estatística \\
\hline & & & & & \\
credit & $-0.0024^{* * *}$ & -5.74 & 0.00 & $\mathrm{R}^{2}$ & 0.7477 \\
gdp/br & -0.0025 & -1.22 & 0.242 & $\mathrm{R}^{2}$ ajustado & 0.6936 \\
inflacp & $0.0023^{* *}$ & 2.75 & 0.016 & Teste $\mathrm{F}$ & 13.83 \\
& & & & $\mathrm{n}$ & 18 \\
\hline
\end{tabular}

Fonte: Elaboração dos autores.

Inicialmente, quando analisamos séries temporais, temos como objetivo averiguar se as séries são estacionárias. Sendo assim, foi realizado o teste Philips-Perron (PP), como apresentado na tabela 3 abaixo. Todas as variáveis são estacionárias em nível, exceto a variável crédito que é estacionária em primeira ordem (acréscimo na nomenclatura da letra d para evidenciar essa prática).

\footnotetext{
$1 * * *$ é significativa a $1 \% ; * *$ é significativa $5 \% ; \mathrm{e}, *$ a $10 \%$. Coeficientes retratam o efeito da variável analisada sobre a variável GINI; Teste-T é o valor econométrico; $\mathrm{P}$-valor mostra se o resultado é confiável; $\mathrm{R}^{2}$ mostra o quanto do GINI é explicado pelo modelo. Variando de o a 1. Quando mais próximo de 1, melhor a explicação do modelo. Teste $\mathrm{F}$ mostra a validade do modelo. N é o número de observações.
} 
Tabela 3: Teste de raiz unitária²

PP

\begin{tabular}{ccc} 
Variável & Defasagem & Valor do teste \\
\hline gini & 2 & $-4,43 * *$ \\
credit & 2 & $-3,18$ \\
dcredit & 2 & $-4,58 * * *$ \\
gdp/br & 2 & $-4,79 * * *$ \\
inflacp & 2 & $-5,28 * * *$ \\
\hline
\end{tabular}

Fonte: Elaboração dos autores.

A regressão foi novamente executada agora levando em consideração a estacionariedade das séries. Logo após a estimação, realizou-se o teste de heterocedasticidade (Breusch-Pagan) e o teste de autocorrelação (Breusch-Godfrey). Os resultados, por sua vez, não rejeitaram a hipótese nula de homocedasticidade e de autocorrelação. A análise dos resultados encontra-se na Tabela 4 a seguir:

Tabela 4: Resultados da regressão com variáveis estacionárias ${ }^{3}$

\begin{tabular}{|c|c|c|c|c|c|}
\hline \multirow{3}{*}{$\frac{\text { Variáveis }}{\text { dcredit }}$} & \multicolumn{4}{|c|}{ MQO } & \\
\hline & \multirow{2}{*}{$\frac{\text { Coeficiente }}{-0.0063^{* *}}$} & \multirow{2}{*}{$\frac{\text { Estatística }-T}{-3.02}$} & \multirow{2}{*}{$\frac{P \text {-valor }}{0.010}$} & \multicolumn{2}{|c|}{ Regressão Estatística } \\
\hline & & & & $\mathrm{R}^{2}$ & 0.4612 \\
\hline$g d p / b r$ & 0.0013 & 0.43 & 0.678 & $\mathrm{R}^{2}$ Ajustado & 0.3368 \\
\hline \multirow[t]{2}{*}{ inflacp } & 0.0003 & 0.13 & 0.9 & Teste-F & 3.71 \\
\hline & & & & $\mathrm{n}$ & 17 \\
\hline
\end{tabular}

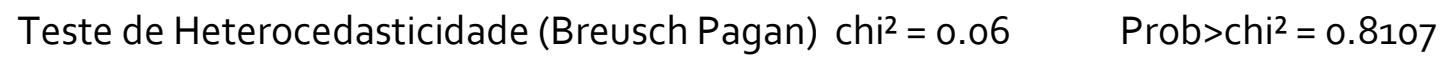

Teste de Autocorrelação (Breusch-Godfrey) $\quad$ chi $^{2}=2.477 \quad{\text { Prob }>c h i^{2}=0.1155}^{2}$

Fonte: Elaboração dos autores.

$2 * * *$ é significativa a $1 \% ; * *$ é significativa $5 \%$; e, * a $10 \%$.

$3 * *$ é significativa $5 \%$. 
A variável de inflação deixa de ser significativa, ao contrário do crédito. O saldo da carteira de crédito em relação ao PIB foi significativo a 5\% e o sinal do coeficiente estimado foi negativo, implicando que o crédito é negativamente correlacionado à desigualdade de renda, ou seja, aumentos na variável. Saldo da carteira de crédito em relação ao PIB (credit) correspondem a diminuições na variável Índice de Gini (gini). Os resultados dessa seção corroboram o argumento da necessidade da presença do sistema financeiro, no tocante à expansão do acesso ao crédito por parte dos mais pobres, a fim de reduzir a desigualdade de renda.

Em um estudo realizado por Bemerguy e Luporini (2006, p. 11,), as autoras analisaram o impacto do desenvolvimento financeiro sobre o nível da renda média dos mais pobres em comparação com a taxa de crescimento da renda média da população como um todo. A análise, que utilizou o crédito privado em relação ao PIB como proxy de desenvolvimento financeiro, concluiu que o acesso aos serviços financeiros é o fator fundamental para que haja alterações no crescimento da renda do quintil mais pobre no Brasil (BEMERGUY; LUPORINI, 2006, p. 11,).

Por fim, as políticas de renda, principalmente aquelas voltadas à expansão do acesso ao crédito é evidenciada em uma pesquisa realizada por Dedecca, Trovão e Souza (2014) como explicação para a tendência da redução da desigualdade de renda corrente e da pobreza "monetária", reduzindo as características sociais desfavoráveis presentes na estrutura social brasileira (DEDECCA; TROVÃO; SOUZA, 2014, p. 24).

\section{Conclusão}

Esse artigo investigou a atuação do setor financeiro brasileiro, no período de 1995 a 2014, como instrumento no combate à disparidade de renda. A análise foi voltada para a atuação do saldo da carteira de crédito, do PIB e da inflação sobre o índice de Gini. Apresentamos que o crédito é negativamente correlacionado à desigualdade de renda.

O mercado de crédito apresenta algumas imperfeições, mas políticas voltadas para a oferta de crédito vêm surgindo e impactando positivamente na vida da população mais pobres. Além disso, com vista em alguns trabalhos discutidos ao longo do artigo, e com os resultados das estimações, o crédito mostra-se como importante ferramenta para garantir uma maior equidade na renda da população. 
Ao longo deste trabalho, pudemos identificar a importância do sistema financeiro juntamente com as variáveis trabalhadas (PIB, taxa de inflação) para a equidade da renda, e assim, redução da desigualdade presente no país. Com destaque para o crédito, uma vez que ele permite o financiamento de famílias de baixa renda e também do investimento dos setores produtivos. Juntamente com os resultados obtidos, outros estudos identificaram que o crédito possui um papel relevante para o crescimento recente da economia brasileira. Desse modo, acreditamos que o presente trabalho possa fornecer subsídios para o debate acerca da desigualdade de renda e mostrar um dos papéis que o setor financeiro pode desempenhar nesse contexto.

\section{Referências}

ABITANTE, Kleber G. Desigualdade no Brasil: um estudo sobre a convergência de renda. ANPEC, classificação JEL: C33, O18, O47, 2007.

BANCO CENTRAL DO BRASIL. Disponível em: <http://www.bcb.gov.br>. Acesso em: mar. 2018.

BARROS DE CASTRO, Lavínia. Privatização, Abertura e Desindexação: A Primeira Metade dos Anos 90 (1990-1994). In: GAMBIAGI, F. et al. Desenvolvimento financeiro e desigualdade de renda: evidências para o caso brasileiro. Universidade Federal Fluminense - UFF. Textos para discussão. Economia. Niterói, 2006.

BARROS, R.; MENDONÇA, R.; HENRIQUES, R. A estabilidade inaceitável: desigualdade e pobreza no Brasil. In: HENRIQUES, R. (Org.). Desigualdade e Pobreza no Brasil, Rio de Janeiro: IPEA, 2000

BARROS, Ricardo Paes de; FOGUEL, Miguel Nathan; ULYSSEA, Gabriel. Desigualdade de renda no Brasil: uma análise da queda recente. Brasília: IPEA, 2006. 2 v.: gráfs, tabs. 446p.

BITTENCOURT, Gilson; MAGALHÃES, Reginaldo; ABRAMOVAY, Ricardo. Informação de crédito: um meio para ampliar o acesso dos mais pobres ao sistema financeiro. Pesquisa \& Debate. São Paulo, v. 16, n. 2 (28), p. 203-248, 2005.

BITTENCOURT, Manoel F. Financial Development and Inequality: Brazil 1985-99. Society for the Study of Economic Inequality, WP jan. de $2006-26$.

BRESSER PEREIRA, Luiz Carlos e NAKANO, Yoshiaki. (1983). Fatores Aceleradores, Mantenedores e Sancionadores da Inflação. In: ENCONTRO NACIONAL DE ECONOMIA DA ANPEC. 10., 1983, Belém. Anais... Belém, dez. 1983.

BRESSER PEREIRA, Luiz Carlos e NAKANO, Yoshiaki. Hiperinflação e estabilização no Brasil: o primeiro Plano Collor. Revista de Economia Política. v. 11, n. 4, p. 44, out.-dez., 1991.

BRESSER-PEREIRA, Luiz Carlos. O governo Dilma frente ao" tripé macroeconômico" e à direita liberal e dependente. Novos estudos CEBRAP. São Paulo, n. 95, p. 5-15, mar. 2013. 
CAGNIN, Rafael Fagundes et al. A gestão macroeconômica do governo Dilma (2011 e 2012). Novos estudos - CEBRAP. São Paulo, nº7, p. 169-185, nov. 2013.

CAMPELLO, Tereza. Uma década derrubando mitos e superando expectativas. In: NERI, Marcelo Côrtes. Programa Bolsa Família: uma década de inclusão e cidadania. Brasília: Ipea, 2013.

CASTRO, L; HERMMAN, J. Economia Brasileira e Contemporânea (1945-2004). Rio de Janeiro: Editora Elsivier/Campus, 2011.

CINTRA, Marcos Antonio Macedo. A Reestruturação Patrimonial do Sistema Bancário e os Ciclos de Crédito entre 1995 e 2005. Política Econômica em Foco, nº 7- nov. 2005/abril. 2006.

CONTRI, André Luis. Uma avaliação da economia brasileira no Governo Dilma. Indicadores Econômicos - FEE, v. 41, n.4, p. 9-20, 2014.

CURADO, Marcelo. Uma avaliação da economia brasileira no Governo Lula. Economia \& Tecnologia. Volume Especial, Ano 07, 2011.

D'ÀVILA, Mariana. Maiores bancos da América Latina são brasileiros. InfoMoney, São Paulo, 2017. Disponível em: https://www.infomoney.com.br/negocios/grandesempresas/noticia/6392183/maiores-bancos-america-latina-sao-brasileiros-confira-ranking.

DE HOLANDA BARBOSA, Fernando. Crescimento da economia: Lula x FHC. Revista Conjuntura Econômica, v. 64, n. 7, p. 68-69, 2010.

DEDECCA, C. S; TROVÃO, C. J. B. M; SOUZA, L. F. Desenvolvimento e equidade. Desafios do crescimento brasileiro. Novos Estudos - CEBRAP. São Paulo, n.98, mar. 2014.

DIEESE. A evolução do crédito na economia brasileira 2008-2013. Nota técnica n. 135, mai. 2014.

DORNBUSCH, Rudiger; FISCHER, Stanley. Macroeconomia. São Paulo: Pearson Makron Books. 2006.

GIAMBIAGI, Fabio. Estabilização, Reformas e Desequilíbrios Macroeconomicos: Os Anos FHC (19952002). In: GAMBIAGI, F; et al. Economia Brasileira e Contemporânea (1945-2004). Editora Elsivier; Campus, 2011.

GIAMBIAGI, Fabio. Rompendo com a Ruptura: O Governo Lula (2003-2010). In: GAMBIAGI, F. et al. Economia Brasileira e Contemporânea (1945-2004) .Editora Elsivier/Campus, 2011.

GUJARATI, Damodar N. \& PORTER, Dawn C. Econometria Básica. 5. ed. São Paulo, 2011.

IPEADATA. Disponível em: <http://www.ipeadata.gov.br>. Acesso em: marc. 2018.

MORA, Mônica. A evolução do crédito no Brasil entre 2003 e 2010). Texto para discussão.. Rio de Janeiro: Instituto de Pesquisa Econômica Aplicada - IPEA, jan. de 2015,

NERI, Marcelo (Coord.). O lado brilhante dos pobres. São Paulo: FGV, set., 2010.

RAMOS, L. A. e VIEIRA, M. L. Desigualdade de rendimentos no Brasil nas décadas de 80 e 90: evolução e principais determinantes. Texto para discussão. Rio de Janeiro: Instituto de Pesquisa Econômica Aplicada - IPEA, no 803, 2001. 
RANGEL, Leonardo Alves; ANDRADE, Joaquim \& DIVINO, José Ângela. Crescimento econômico e deisgualdade de renda no Brasil de 1991 a 2000: - uma análise das áreas mínimas comparáveis. Texto para discussão. Rio de Janeiro: Instituto de Pesquisa Econômica Aplicada - IPEA, n. 1312, nov. de 2007.

RODRIGUES, Mauro e SABBADINI, Ricardo. Impactos da inflação sobre a desigualdade de renda. ANPEC, Área 3, classificação JEL: D30, E31, 2010.

SOUZA, Jessé. Para especialista em desigualdade, a chamada nova classe média é fetiche do número. Agência Brasil. Entrevista concedida em 16 de out., 2010.

STIGLITZ, Joseph. Valor, São Paulo, p. C12, 18.jun.2004.

TEIXEIRA, Rodrigo Alvez; PINTO, Eduardo Costa. A economia política dos governos FHC, Lula e Dilma: dominância financeira, bloco no poder e desenvolvimento econômico. Economia e Sociedade. Campinas, v. 21, n. 3 (46), p. 909-941, dez. 2012.

THE WORLD BANK. Disponível em: <http://www.worldbank.org>. Acesso em: mar. 2018.

\section{Chinara Mendes Schinaider (UFV)}

Mestranda em economia da UFV. Graduanda em Ciências Econômicas pela Universidade Federal de Ouro Preto - MG, com ênfase em Desenvolvimento Econômico e Social. Atualmente é bolsista do Programa de Educação Tutorial (PET ICSA - Conexão de Saberes), objetivando atividades voltadas para o ensino, cultura, pesquisa e extensão e voluntária na modalidade Iniciação Científica (IC) pelo PIVIC/UFOP. E-mail: chinaraschinaider@hotmail.com

\section{Luccas Assis Attílio (UFOP)}

Professor de Economia da Universidade Federal de Ouro Preto (UFOP), do Departamento de Ciências Econômicas (DEECO), no Instituto de Ciências Sociais Aplicadas (ICSA). Formado em Ciências Econômicas pela Universidade Federal de Viçosa (UFV) e Mestre em Economia pela Universidade Federal de Minas Gerais (UFMG) no Centro de Desenvolvimento e Planejamento Regional (CEDEPLAR). Realiza pesquisas na área de macroeconomia, se concentrando nos tópicos crescimento econômico e sistema financeiro. Foi membro do grupo de pesquisa GERE (Grupo de Estudo da Racionalidade Ecológica). Desde 2015 é membro do LEMTe (Laboratório de Estudos sobre Moeda e Território) da UFMG. Trabalhou no Instituto Brasileiro de Geografia e Estatística (IBGE) em 2010 e na Fundação de Amparo à Pesquisa de Minas Gerais (FAPEMIG) em 2016. Foi colunista do site Dataviva.info entre 2016 e 2017. E-mail: luccas.ufop@gmail.com 